\title{
XRD And Extensometric Measurements Of Residual Stresses And Its Comparision To Finite Elements Analysis On Ligth Alloy Wheels
}

\author{
Cione, F.C. ${ }^{* 1}$; Rossi, J.L. ${ }^{1 ;}$ Martinez, L.G. ${ }^{1}$; Delijaicov, S. ${ }^{2}$ \\ 1 Instituto de Pesquisas Energéticas e Nucleares, IPEN - CNEN/SP \\ 2 Centro Universitário da FEI
}

\begin{abstract}
This study had as proposal to improve the knowledge of the residual stresses phenomena in wheels and expand the database of the computer systems from finite elements analysis (FEA). $\mathrm{X}$-ray diffraction (XRD) was used to acquire and make this information available. Now engineering specifications, manufacturing procedures, inspection and quality controls require the evaluation of the residual stress of critical parts of components. This is becoming a commonplace such as the demands for mechanical properties data. The residual stress in metal and alloy components arises as a result of manufacturing processes by which was attained the shape of the desired component. The work was undertaken aiming, specifically, the evaluation of light-alloy wheels cast of AlSi7 alloy for use in passengers cars. The residual stress values from XRD and hole drilling method of the experimental tests on the spokes were compared with simulation data. Sometimes simulation system needs correction of data of the effect of plasticity. Those presented values of residual stress demonstrated the existence of convergence to the values of experimental tests and values calculated using FEA simulation software. The relevance of the present study and research on residual stresses meets the required effort towards the safety improvements in car's wheel industry.
\end{abstract}

Keywords: Residual stress, X-ray diffraction, strain gages, extensometer, aluminum wheels.

\section{Introduction}

This paper is a study of the residual stress in automotive wheels, using XDR and strain gages experimental testing in comparison to simulation analysis using finite element (FEA). The results of residual stress experiments will retrofit FEA simulation and the total load over wheels will be evaluated to avoid fracture under operation. Although the FEA provides the simulation advantage, it is required experimental procedures to verify and validate the simulation (Fig. 1). Usually it is distinguish three types of stress states, according to their size radii [1]. First: macroscopic, high range stresses acting on a macroscopic region covering. Second: structural micro-stress, located in a wide number of grains and its surroundings. Third: A little amount of grains by focusing molecular structure of crystal, involving the structure at the atomic level [2]. For each type it is associate one or a combination of methods to get better response 
from the experiments. The most usual methods are X-ray and neutron diffraction, blind hole, cut ring, cut by section removing layers. In this paper it is presented the methods of X-ray diffraction and hole drilling to analyses of local residual stress data. The XRD is considered a nondestructive method for superficial residual stress measurements and it is a group of grain size average [3]. When a part or portion below the surface is the interest region, material must be removed and the XRD method becomes destructive. The XRD method was multi-angle with is possible to do more precise determination of $\sigma_{\varnothing}$ using more than two $\psi$ orientations and plotting the measured strain values for each $\psi$ orientation as function of $\sin ^{2} \psi$ [4]. Applied stress is usually highest at the surface where the failures start over. All experiments were undertaken in residual tension auto-static equilibrium, where the resultant internal forces and moments are zero. It is known that the tensile residual stress can be added vectorially to a static load by the principle of superposition (equation 1).

$$
\sigma_{\mathrm{n}}=\sigma_{\mathrm{A}}+\sigma_{\mathrm{r}}
$$

The hole drilling method is in situ and involves the removal of material under tension by making a blind hole depth, always smaller than the diameter of the drill $(0.4 \mathrm{D})$ in the center of the rosette strain gauge and measuring the deformation occurred in the region adjacent to the hole [5]. The method by itself induces a residual stress and needs an initial calibration. An advantage of using the rosette with central hole is a better sampling of the main deformation.

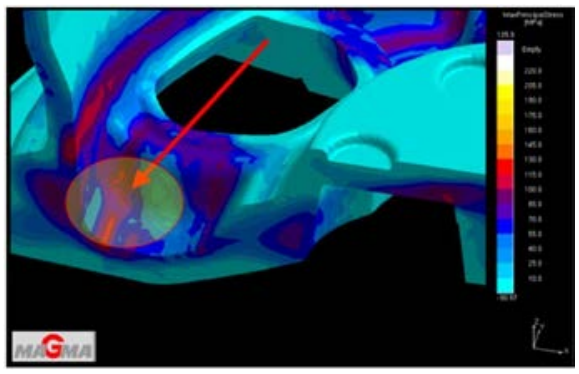

Figure 1: FEA simulations.

\section{Experimental Methods}

\subsection{XRD Method}

The measured stress is only normal stress. The experimental procedures from the XRD take data over five groups of wheel parts. There is shear stress present too but it is not directly measured by DRX. In this work was applied Xray beam over four small part of straight area of the wheel. Those parts were selected from previous critical area pointed by using software simulation. After XRD measurements over those selected area, the area was prepare to other method of measurement. The gages were applied over the same area (Fig. 2) that was used to XRD measurements. The main difference between $X R D$ residual stress measurement and gages measurements is that the gages shows a portion of deformation (strain) under its substrate area.

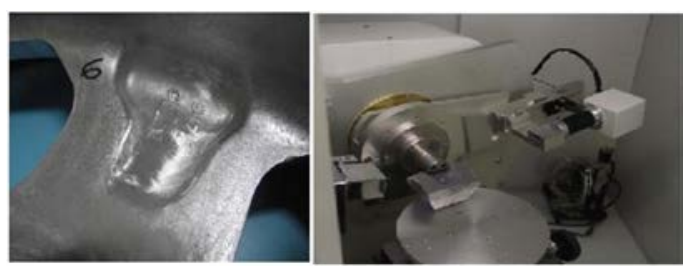

Figure 2: XRD experimental method trial.

\subsection{Hole Drilling Methods,}

The hole drilling method is widely used to measure average residual stress. There are three gages in one device for hole drilling method. This method is destructive because a $0.3 \mathrm{~mm}$ in deep drilling is required. The technique use tension relief to measured deformation under the gages. In general, tension relief take place larger and deeper than the XRD method even measure. In this case to obtain residual stress, deformation value is used to do a multiplication by aluminum (E) Young's modulus (equation 2).

$$
\sigma=\varepsilon \mathrm{E} \quad(2)
$$

In the classical system of hole drilling method (blind hole) a rosette type strain gauges is used (ASTM E 837) that have a center mark locator for drilling (Fig. 3). 

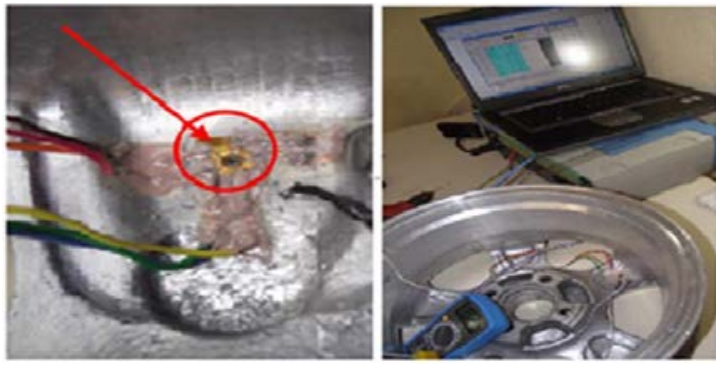

Figure 3: Hole drilling method experimental sequence of trial.

To acquire residual stress with hole drilling method was a three gages with specific geometric accomplish in one rosetti device. The equipment used to acquire data from gages was setup to integral method stress. The integral calculus was use in the analysis of strain gauge experiments show the data collected. The equipment used to acquire data was ADS-2164 and software to analyze was AqDados 7.2 Lynx (Fig. 5).

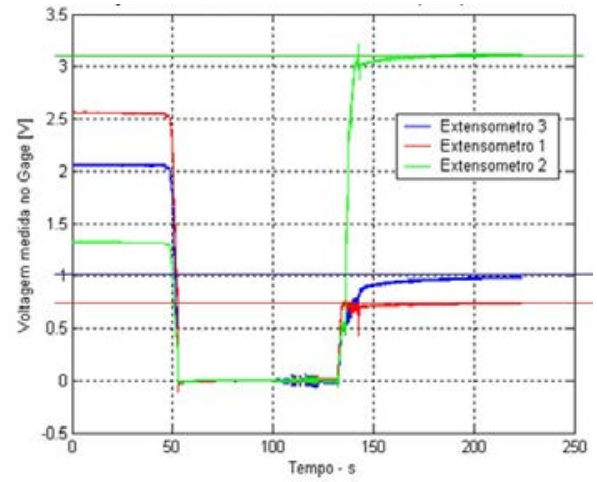

Figure 5: Method of blind hole - graphics response.

\section{Results}

\subsection{XRD METHODS RESULTS \\ To calculate the average of deformation occurred in the micro region of wheel the analysis of those data was processed using a Foxit computer system as shown in Fig. 4. The residual stress average value shows $-186,435$ MPa with a compression tension mode.}

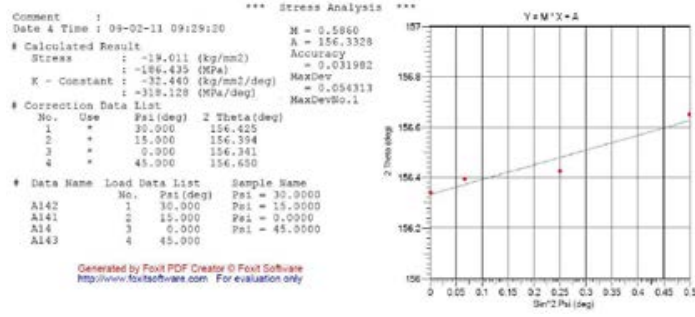

Figure 4: XRD Residual Stress Results by Foxit Software.

3.2 Hole Drilling Methods.

The analyzes shows during 225 s, divided into six distinct elapsed times: (1) 0-45 s calibration setup of the "zero" signal level is a pre-punching process; (2) 45-55 s punch; (3) 55-105 s waiting for the positioning of the drill; (4) 105-130 s on the positioning of the drilling rosette; (5) 130-150 s drilling process; (6) $150-225$ s stabilization the surface. Calculated the values of microdeformations in each stain gauge direction (Fig. $6)$.

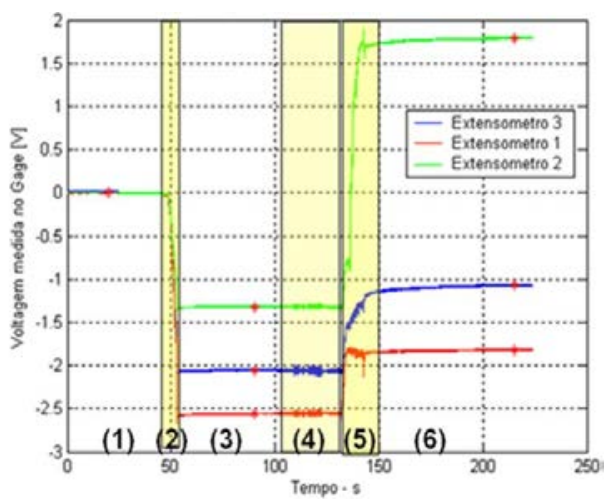

Figure 6: Method of blind hole - graphics analyzes. 


\section{Conclusion}

In this work the results and analysis of experimental data from XRD indicate a residual stresses in compression mode as FEA indicate. The hole drilling techniques indicated traction mode. The values calculated with both experimental methods were compatible and convergent with FEA simulation. The general behavior of stress field seems to be convergent with similarity to those obtained using FEA simulation (table 1).

\begin{tabular}{|c|c|c|}
\hline Method & $\begin{array}{c}\text { Residual Strees } \\
\text { Value }(\mathrm{MPa})\end{array}$ & $\begin{array}{c}\text { Residual Stress } \\
\text { Module }\end{array}$ \\
\hline FEA & $175,0+/-10$ & Compression \\
\hline XRD & 186,435 & Compression \\
\hline Blind Hole & $195,3+/-0,5$ & Tration \\
\hline
\end{tabular}

Table 1 : Residual stress behavior

Even the region selected was the same the area of wheel on each experimental procedure is quiet difference. This difference is enough to give opposites residual stress module. There is a need of conducting further experiments to confirm the trend toward the simulation results data, and to investigate new approaches.

\section{References}

[1] BONET J., WOOD R. D., Non Linear Continuum Mechanics for Finite Element Analysis, Cambridge - USA, Cambridge University Press, USA, 1997.

[2] MACKERLE J., FEM And BEM Analysis And Modeling Of Residual Stresses. Finite Elements in Analysis and Design, Linköping - Sweden, 2001

[3] CULLITY, B.D., Elements of X-Ray Diffraction Second Ediction, Addison Wesley Inc., New York, NY - USA, 2001, ISBN 0-20101174-3.

[4] HILLEY, M.E., Residual Stress Measurement by X-Ray Diffraction, SAE International HS-784, Global Mobility Database, Warrendale - PA, USA, 2003, ISBN 0-7680-1069-1.
[5] BEGHINI, M.; BERTINI, I.; SANTUS, C. A Procedure for Evaluating High Residual Stresses Using the Blind Hole Drilling Method, Including the Effect of Plasticity. Universidade de Pisa. Pisa - Italy, p. 301 -314. 2009. 